\title{
Un exemple de plurilinguisme vécu au quotidien
}

\section{Marie-Thérèse Weber}

\section{OpenEdition}

\section{Journals}

Édition électronique

URL : http://journals.openedition.org/esp/1374

DOI : 10.4000/esp. 1374

ISSN : 2532-0319

\section{Éditeur}

Centre d'Information sur l'Éducation Bilingue et Plurilingue

\section{Édition imprimée}

Date de publication : 1 décembre 2017

Pagination : $9-10$

ISSN : 1127-266X

\section{Référence électronique}

Marie-Thérèse Weber, « Un exemple de plurilinguisme vécu au quotidien », Éducation et sociétés

plurilingues [En ligne], 43 | 2017, mis en ligne le 01 février 2019, consulté le 15 septembre 2020. URL : http://journals.openedition.org/esp/1374 


\section{UN EXEMPLE DE PLURILINGUISME VÉCU AU QUOTIDIEN}

\section{Marie-Thérèse WEBER}

Le circostanze della vita conducono i membri di una famiglia a vivere con diverse lingue in contemporanea e in alternanza.

Parole chiave: plurilinguismo, percorsi di vita, Sirzzera, Tunisia, francese, tedesco, dialetto, arabo.

Life circumstances cause the members of one family to lead a life in several languages, both simultaneously and alternatingly.

Keyreords: plurilingualism, life course, Switzerland, Tunisia, French, German, dialect, Arabic

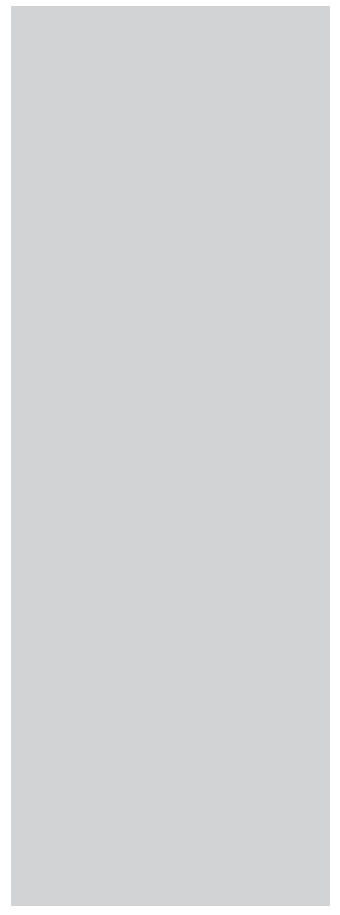

Ophia $\left(^{*}\right)$ vit avec son mari $\operatorname{Ali}\left(^{*}\right)$ et leur fille Nejma $(*)$, âgée de douze ans, à Fribourg, ville suisse bilingue. Jeune femme dynamique, elle travaille, en tant que traductrice à Berne, ville voisine située en Suisse alémanique. Le parcours de vie et les activités professionnelles de Sophia illustrent un plurilinguisme vécu au quotidien.

Née à Berne d'une mère suisse alémanique et d'un père tunisien, Sophia, qui a un frère cadet, a passé les deux premières années de sa vie à Genève. La langue de communication de la famille était alors le français. Après ce séjour en Suisse, le couple partit avec ses enfants en Tunisie où la mère de Sophia tomba gravement malade. Sur ces entrefaites, le père décida d'aller avec les siens en Allemagne, espérant une meilleure prise en charge médicale de son épouse. C'est dans ce pays que la fillette fut pour la première fois confrontée au Hochdeutsch, mais elle y fréquenta une école francophone. En famille, la langue de communication était habituellement le français; cependant, la maman parlait parfois en allemand à son mari. Les enfants, eux, s'adressaient le plus souvent en allemand à leur mère, tandis qu'entre eux ils communiquaient en français.

Sophia avait neuf ans quand sa mère mourut; peu après, le père retourna avec ses enfants en Tunisie où ceux-ci poursuivirent leur scolarité en français. Le père de Sophia se remaria avec une Tunisienne qui avait deux enfants ayant à peu près le même âge que Sophia et son frère. L'arabe devint alors la langue utilisée en famille. Après l'obtention du baccalauréat français, Sophia revint en Suisse et vécut chez ses 
Un exemple de plurilinguisme vécu au quotidien

M.-T. WEBER grands-parents maternels installés à Berne. Originaires de la Suisse centrale, ceux-ci, en plus du Hochdeutsch, parlaient un dialecte suisse alémanique. Sophia entreprit des études de biologie à l'université bilingue de Fribourg où elle suivit des cours en français et en allemand. Faisant la navette entre Berne et Fribourg, elle continuait d'habiter chez ses grands-parents. À la fin de ses études universitaires, elle épousa un Libanais qui avait déjà vécu plusieurs années à Berne où le jeune couple s'installa. De cette union naquit Nejma $\left(^{*}\right)$.

Trois ans plus tard, la famille déménagea à Fribourg. À l'exception de quelques mandats ponctuels, Sophia n'eut pas d'activité professionnelle jusqu'au moment où sa fille commença l'école primaire. En famille, on a toujours parlé arabe. Mais pour être initiée au français, Nejma fréquenta pendant deux ans, à raison de deux après-midi par semaine, une école maternelle accueillant des enfants francophones. À son entrée à l'école primaire francophone, elle n'eut aucune difficulté linguistique. Le programme, dès la troisième année scolaire, comprend aussi des leçons d'allemand et, à la fin de l'école primaire, Nejma sera initiée à l'anglais. La fillette passe la plus grande partie de ses vacances en Tunisie et au Liban dans sa famille, où elle parle arabe et est en contact avec la culture de ces pays-là. Quant à Sophia, elle travaille à 70\%, à Berne, dans une compagnic d'assurances en tant que traductrice allemand/français, français/allemand. En outre, vu ses connaissances linguistiques, particulièrement en arabe, elle est souvent appelée par la Croix-Rouge et Caritas, en sa qualité d'interprète communautaire, auprès de migrants, notamment pour des démarches administratives, des questions juridiques ou pour accompagner des patients chez le médecin, à l'hôpital. Ali, lui, travaille dans un milieu bilingue français/allemand, mais parle souvent arabe avec des amis.

Pour Sophia, l'apprentissage des langues s'est fait au gré des circonstances de son enfance, elle a été plongée dans différentes cultures et s'en est imprégnée. À l'aise dans les divers milieux qu'elle fréquente, soit dans le cadre de son travail professionnel, soit durant ses loisirs, elle semble jongler avec les langues (arabe, français, allemand, dialecte suisse alémanique). Bien que par son domicile et ses activités professionnelles, elle baigne dans un environnement français/allemand, elle reconnaît que l'arabe reste pour elle la langue des émotions. Cette famille vit donc en harmonie avec différentes langues et cultures. La pratique du plurilinguisme fait partie de la vie quotidienne de Sophia et, heureux augure, du haut de ses douze ans, Nejma est déjà fort intéressée par l'apprentissage des langues.

* Prénom fictif

Article paru dans Éducation et Sociétés Plurilingues n³2, pp. 89-90, en 2012. 